\title{
More winds of change: the provision of cardiological services in the United Kingdom
}

The wind of change is blowing through this continent.

Harold Macmillan's famous speech to the South African Houses of Parliament in 1960 was born of observation not prophecy. Yet up to that point, and well beyond, many in positions of influence failed to accept the implications of change and much avoidable damage ensued. We must not make the same mistake by ignoring irresistible forces that will change the pattern of the provision of cardiological services in the United Kingdom.

The provision of health care in the United Kingdom is undergoing a revolution that is unparalleled since the inception of the National Health Service. Cardiology shares the perturbations of the internal market, the pressures for a consultant based service, and the implications of the Calman report on training. But uniquely the specialty is facing another ground swell of change that has long been foreseen but never formally planned or directed. While tertiary centres must continue to provide all major interventional facilities, cardiologists in district general hospitals are increasingly assuming a pivotal role in highly specialised diagnosis and treatment that depends not only on clinical expertise but also on a wide range of technological skills. The report in this issue of the British Heart fournal on cardiology in the district hospital $^{1}$ reflects this wind of change in the specialty and merits careful consideration. The implications for training are of particular importance. The Royal Colleges' Specialist Advisory Committee for cardiovascular medicine together with the Training and Manpower Committee of the British Cardiac Society recognise the need for important modifications not only in the methods of training - soon to be more structured-but also in the objectives. The emphasis within most institutions will shift from training for a career in the tertiary centres to training for the extended range of cardiological practice that is the evolving pattern in district general hospitals.

Historically, too little attention has been paid to the content and objectives of training programmes. Progress has been made in recent years with the increasing influence of the Royal Colleges' Joint Committee on Higher Medical Training (JCHMT) and its individual Specialist Advisory Committees. But the system remains flawed: examples can readily illustrate the failure of the present system to meet the needs of the modern district cardiologist. Fundamentally we still have an apprenticeship system that should long have been considered outmoded. Inevitably, new consultants have been created in the image of those who trained them, and in recent years most trainers within our tertiary centres have been invasive and, later, interventional cardiologists. But trainees have hardly been reluctant to follow the lure of intervention. Their enthusiasm is understandable: until recently the enormous professional satisfaction of correcting a structural defect was the province only of surgeons and often envied as such; skills in angioplasty, valvuloplasty, and ablation that powerfully influence outcome are appropriately highly prized; and the potential for financial reward in the private sector cannot be overlooked. But for those destined to become cardiologists in district general hospitals training in interventional skills has little relevance. In contrast with intervention, the skills of echocardiography, which in the tertiary centres have often remained within the competent hands of technicians and physicists, are less highly prized by many trainee cardiologists. Some otherwise excellent programmes at registrar or senior registrar level make no formal provision for training in echocardiography. Skill may then be acquired only in response to the variable needs of service provision. Yet echocardiography is of crucial importance, not only in tertiary centres that tend to be well provided, but also in district general hospitals where expertise at technician level sometimes needs to be developed and maintained. Echocardiography is only one example of the requirements for cardiology in district hospitals. They need specialists with a wide range of interests and skills-many of which are highlighted in the report. In addition to acute cardiac care and all routine methods of non-invasive assessment, knowledge is needed in epidemiology, congenital heart disease, prevention, rehabilitation, and resuscitation-as well as in management. At the latest count within the United Kingdom ${ }^{2}$ there are 145 adult posts in tertiary centres for which subspecialisation may be appropriate and 232 within district general hospitals needing a broad base of skills to which must be added the few general cardiologists who will still be needed in teaching hospitals. In the absence of a more structured training programme the needs of the larger group are not being well met.

The scope of cardiological practice within district general hospitals is, however, expanding. The working party report stresses that invasive skills, notably coronary angiography and permanent pacemaker implantation, are now often appropriate to and increasingly expected of district cardiologists. Some larger hospitals can provide facilities with adequate technical and nursing support and a workload large enough to maintain a high level of proficiency. Cardiologists in hospitals without these attributes may have sessions in neighbouring tertiary or district centres where they can undertake invasive procedures. Continuity of care for patients as well as professional satisfaction for specialists can be enhanced by liaison of this type. There remains a place, of course, for cardiologists whose inherent abilities are better suited to non-invasive than invasive work-especially as larger districts recognise the need for two or more physicians trained in the specialty. Progress within training grades has often been difficult and sometimes impossible for such individuals under the apprenticeship system-with the potential for frustration and injustice to trainees and a loss of valuable expertise to the specialty.

Last month the British Cardiac Society Newsletter (page 211) provided a first public glimpse of the proposals being put forward for the new training pro- 
grammes designed with three objectives: to counter the shortcomings discussed above, to address the requirements of the Calman report, and to be consistent with the emerging requirements of the European Board in Cardiology which has a membership composed of representatives of the European Union of Specialists (UEMS) and the European Society of Cardiology. The proposals were presented only in outline, but detailed guidelines have been prepared by the specialist advisory committee in cardiovascular medicine and will be published in due course. Training in the new unified grade (to replace that of registrar and senior registrar) will be acquired both in a general hospital setting and in a tertiary centre. Although the need for some flexibility is recognised, the general structure of the programme will be prescribed clearly and the needs of the district cardiologist will be addressed comprehensively. Trainees will make a choice for their final year - in the knowledge of career opportunities that will be available- between more general internal medicine (to meet the requirements of the general hospital) or in more specialist training within a subspecialty (to prepare for a career in a tertiary centre). Nominated trainers, formal assessments, required numbers for procedures, and log books to provide a record of practice will all be mandatory. The new six year programme was foreshadowed by the changes introduced only recently for cardiology by the Training and Manpower committee ${ }^{3}$ and accepted by JCHMT. The need for a structured programme was also being discussed, and the affiliated groups (that represent the major subspecialties within the British Cardiac Society) had been approached for advice on detailed training needs long before the Calman report was published. These moves have given cardiology a head start on some other specialties that has been particularly valuable because of the short time envisaged for consultation.

What will be the pattern of the provision of cardiological services when the wind of change has blown through the system? We believe that there will be fewer district general hospitals. Whether or not this is desirable, the result should be more specialists at consultant and trainee level within each hospital that remains. Most general hospitals are likely to be offering invasive coronary angiography and permanent pacemaker implantation as well as a wide range of non-invasive procedures-such as transoesophageal echocardiography and nuclear cardiology. Magnetic resonance imaging will be replacing some investigational procedures and opening new vistas of diagnostic capability. With this prospect in view it is surprising that many of our existing senior registrars opt not to apply for posts in district general hospitals, preferring to await opportunities within tertiary centres where interventional procedures will be available. These opportunities will be few, representing no more than $20 \%$ vacancies expected within the next five years. Trainees should ponder on this statistic and also the attraction of a career built around continuing responsibility for patient care that uses the wide range of skills employed now by most consultant cardiologists-because in future this will be a pattern found most commonly in the districts. Alternatively they may seek a future in providing a highly skilled service in a subspecialty with less involvement in continuing patient care. Both types of career have undoubted attractions, but some trainees expect a combination that will not usually be available.

DOUGLAS CHAMBERLAIN
MICHAEL WEBB-PEPLOE
ROGER HALL
JOHN PARKER

for the Training and Manpower Committee British Cardiac Society

1 A report of a working group of the British Cardiac Society. Cardiology in the district hospital. Br Heart f 1994;72:303-8.

2 Chamberlain D, Parker J, Balcon $R$, et al. Eighth survey of staffing in cardiology in the United Kingdom 1992. Br Heart $\mathcal{F} 1994 ; 71: 492-500$.

3 Chamberlain D, Julian D, Sleight $P$, Sowton E. Proposals for a new training programme for cardiology. Br Heart $\mathcal{F}$ 1990;63:317-20. 